\title{
Complete response to the combination of Lenvatinib and Pembrolizumab in an advanced hepatocellular carcinoma patient: a case report
}

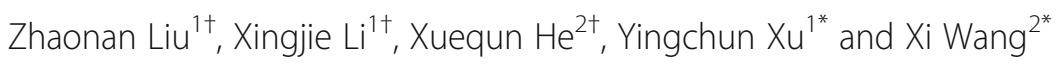

\begin{abstract}
Background: The majority of patients diagnosed with hepatocellular carcinoma (HCC) have advanced diseases and many are not eligible for curative therapies.

Case presentation: We report a rare case of HCC from a patient who had a complete response (CR) with the use of combination of Lenvatinib and Pembrolizumab. A 63-year-old man presented at the hospital with serious abdominal pain and was found to have a mass with heterogeneous enhancement and with hemorrhage in segment III of the liver after the examination of abdominal computerized tomography (CT) scan. The patient's history of viral hepatitis B infection, liver cirrhosis and the a-fetoprotein (AFP) level of $14,429.3 \mathrm{ng} / \mathrm{ml}$ supported the clinical diagnosis of HCC and laboratory results demonstrated liver function damage status (Child-Pugh class B, Score 8). The patient first received hepatic arterial embolization treatment on 28th November 2017. At this stage supportive care was recommended for poor liver function. In February 2018, combined immunotherapy of Pembrolizumab (2 mg/kg, q3w) and Lenvatinib ( 8 mg-4 mg, qd) were performed. Nine months following the treatment he had a CR and now, 22 months since the initial treatment, there is no clinical evidence of disease progression. The current overall survival is 22 months.

Conclusions: $\mathrm{HCC}$ is a potentially lethal malignant tumor and the combination of immunotherapy plus anti-angiogenic inhibitors shows promising outcome for advanced diseases.
\end{abstract}

Keywords: Hepatocellular carcinoma, Immunotherapy, Lenvatinib, Pembrolizumab

\section{Background}

Hepatocellular carcinoma (HCC) is the fifth leading cause of cancer death in the United States with a 5-year survival rate of $18 \%$ for all stages [1] and its incidence rate is rising faster than that of any other cancer in both men and women [2]. Rates of both incidence (18.3 per $100,000)$ and mortality $(17.1$ per 100,000$)$ are 2 to 3 times higher in China than those estimated in most other world regions [1]. The major risk factors of HCC vary from region to region. The key determinants in China are chronic hepatitis B virus (HBV) infection and

\footnotetext{
*Correspondence: xiaoxu2384@163.com; d.wangxi@hotmail.com

${ }^{\dagger}$ Zhaonan Liu, Xingjie Li and Xue-Qun He are co-first author.

'Department of Oncology, Shanghai Renji Hospital, Shanghai Jiaotong

University School of Medicine, Shanghai 200127, People's Republic of China

${ }^{2}$ Department of Oncology, the 903rd Hospital of PLA, 14 Lingyin Road,

Hangzhou 310013, China
}

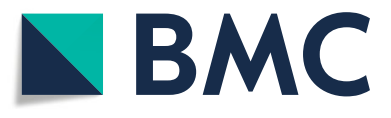

(c) The Author(s). 2019 Open Access This article is distributed under the terms of the Creative Commons Attribution 4.0 International License (http://creativecommons.org/licenses/by/4.0/), which permits unrestricted use, distribution, and

reproduction in any medium, provided you give appropriate credit to the original author(s) and the source, provide a link to the Creative Commons license, and indicate if changes were made. The Creative Commons Public Domain Dedication waiver (http://creativecommons.org/publicdomain/zero/1.0/) applies to the data made available in this article, unless otherwise stated.
China are at younger ages and with cirrhosis.

Surgery is usually considered the treatment of choice for early disease; however, most patients have locally advanced or metastatic $\mathrm{HCC}$ at diagnosis in which case treatments are limited. Furthermore, with the wide range of local regional therapies available to patients with unresectable HCC (uHCC), evidence for favorable systemic therapy for metastatic disease on overall survival (OS) is lacking. Cytotoxic chemotherapies have reported to have low response rates. Oral multi-kinase inhibitors that suppress tumor cell proliferation and angiogenesis in HCC have been approved. Currently, the first line options for uHCC include Sorafenib and Lenvatinib, and second line options are formed by Regorafenib and Cabozantinib. Clinical studies with Nivolumab (Checkmate 040 trial) or 
Pembrolizumab (KEYNOTE-224) also have promising data for patients with advanced HCC who progressed on or after Sorafenib. The rationale for the combination of Lenvatinib and Pembrolizumab has been illustrated in preclinical studies. Clinical studies of the combination treatment had not been published until June 2018. Preliminary data of the Phase $\mathrm{Ib}$ clinical trial of combination treatment (PEM plus LEN) in HCC patients have been published as Keynote-524 in 2019 in the journal of the American Association for Cancer Research (AACR).

To evaluate clinical efficacy of the combination rationale including immune checkpoint inhibitors and multikinase inhibitors, we report a case of HCC with poor liver function in the setting of cirrhosis from HBV infection responding dramatically to the combination treatment of Pembrolizumab and Lenvatinib after initial hepatic arterial embolization (HAE) and we hope to explore further study for anti-PD-1 therapy and multikinase targeted therapy combination for HCC treatment in the future.

\section{Case description}

Our patient, a 63-year-old male with a history of chronic HBV infection for 18 years, presented to the emergency department with severe abdominal pain and flatulence in November 2017. Enhanced abdominal CT showed a heterogeneous irregular mass with the largest measuring up to $5.0 * 3.8 \mathrm{~cm}$ in size in segment 3 within the left lobe of liver(Fig. 1a-c). Hepatocellular carcinoma (HCC) with hemorrhage and peritoneal effusion should be considered first. The CT scan also revealed liver cirrhosis, splenomegaly, portal hypertension with multiple collateral circulations (Fig. 1d) and partial thrombosis of the left portal vein (Fig. 1e, f). The laboratory test data revealed serum a-fetoprotein (AFP) was $14,429.3 \mathrm{ng} / \mathrm{ml}$ and HBV DNA level of $2.37^{*} 10^{\wedge} 3 \mathrm{IU} / \mathrm{ml}$. The patient was confirmed with the clinical diagnosis of Barcelona Clinic Liver Cancer (BCLC) C and Child-Pugh class B (Score 8) (Table 1) HCC with the background of cirrhosis secondary to viral $B$ infection. The patient first received HAE and then discharged with an HBV DNA level below $30 \mathrm{IU} / \mathrm{ml}$ after antiviral treatment with entecavir. He had radiographic progression 2 months later (Fig. 2a) with poor liver function (Child-Pugh class B 7) (Table 1). For Sorafenib, $400 \mathrm{mg}$ twice daily was only recommended for HCC with liver function of ChildPugh class A. For lack of an available clinical trial, the patient was prescribed off-label immunotherapy based on the phase I/II data mentioned above (KEYNOTE224). He was recommended to take Pembrolizumab 100 $\mathrm{mg}(2 \mathrm{mg} / \mathrm{kg}$, q3w) on Feb. 8th 2018, which was well tolerated. Baseline computed tomography (CT) showed one large liver lesion and extrahepatic hilar lymph node metastasis (Fig. 2a). After one cycle of Pembrolizumab, his AFP increased to $55,107.82 \mathrm{ng} / \mathrm{ml}$ compared to 47 , $739.14 \mathrm{ng} / \mathrm{ml}$ before Pembrolizumab was administered (Fig. 2b). The patient was recommended to continue on Pembrolizumab due to the stable clinical status of the

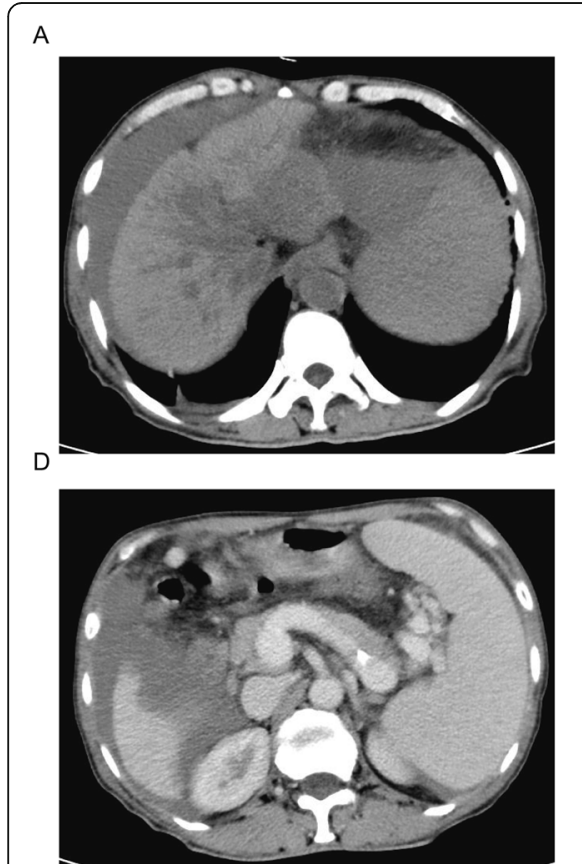

B

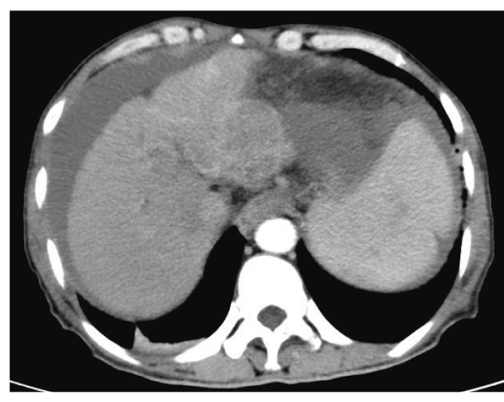

E

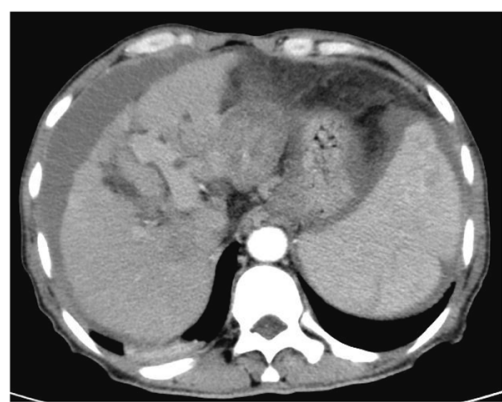

C

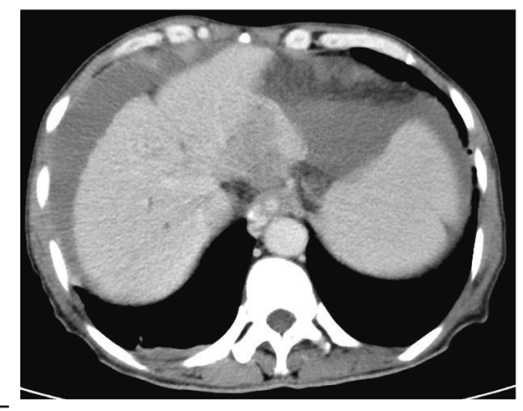

$\mathrm{F}$

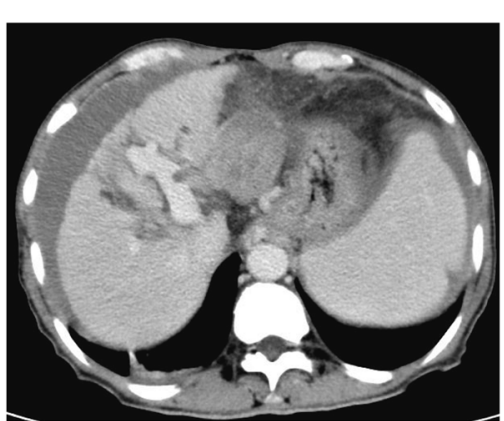

Fig. 1 CT of the abdomen showing the segment 3 liver lesions at diagnosis. a The characteristics of liver mass in plain scan; $\mathbf{b}$ Liver mass in arterial phase; c Liver mass in portal phase; $\mathbf{d}$ Multiple collateral circulations; e Partial thrombosis of the left portal vein in arterial phase; $\mathbf{f}$ Partial thrombosis of the left portal vein in portal phase 
Table 1 The Child-Pugh class level, HBV DNA level and full blood test analysis corresponding to pembrolizumab and lenvatinib combination therapy

\begin{tabular}{|c|c|c|c|c|c|c|c|c|c|c|c|c|}
\hline Date & $\mathrm{ALB}(\mathrm{g} / \mathrm{l})$ & HE & PT & INR & Ascites & T-BIL & Score & HBV-DNA & WBC(10^9/L) & $\mathrm{GR}\left(10^{\wedge} 9 / \mathrm{L}\right)$ & $\mathrm{HGB}(\mathrm{g} / \mathrm{L})$ & $\operatorname{PLT}\left(10^{\wedge} 9 / \mathrm{L}\right)$ \\
\hline 17.11 .27 & 30.4 & $\mathrm{~N}$ & 15.3 & 1.35 & $Y$ & 16.4 & 8 & 2370 & 1.3 & 0.58 & 112 & 42 \\
\hline 18.2.7 & 31.6 & $\mathrm{~N}$ & 15.4 & 1.3 & N & 17.3 & 7 & $<30$ & 1.45 & 0.81 & 118 & 43 \\
\hline 18.3.2 & 33.0 & $\mathrm{~N}$ & 15.6 & 1.31 & N & 23.6 & 7 & $<30$ & 1.89 & 0.99 & 126 & 48 \\
\hline 18.4.8 & 25 & $\mathrm{~N}$ & 20.4 & 1.73 & N & 32.7 & 10 & 38.7 & 1.62 & 0.67 & 127 & 21 \\
\hline 18.6.11 & 26 & $\mathrm{~N}$ & 16.6 & 1.4 & N & 31.1 & 7 & $<20$ & 1.21 & 0.58 & 110 & 23 \\
\hline 18.7.9 & 29.7 & $\mathrm{~N}$ & 16.5 & 1.39 & N & 25.3 & 7 & / & 1.26 & 0.71 & 113 & 34 \\
\hline 18.7 .31 & 30.3 & $\mathrm{~N}$ & 16.6 & 1.4 & N & 30.8 & 7 & / & 1.42 & 0.72 & 120 & 21 \\
\hline 18.8 .22 & 29.2 & $\mathrm{~N}$ & 16.2 & 1.36 & N & 20.5 & 7 & $<20$ & 0.9 & 0.42 & 106 & 25 \\
\hline 18.11 .9 & 31.8 & $\mathrm{~N}$ & 15.4 & 1.29 & N & 21.6 & 7 & $<20$ & 1.33 & 0.69 & 117 & 27 \\
\hline
\end{tabular}

patient, and the possibility of pseudoprogression. However, the patient was so worried about the potential progression of his cancer that he started to take Lenvatinib in addition to Pembrolizumab from Mar. 10th for $8 \mathrm{mg}$ per day at home. Adverse effects including grade III diarrhea, grade IV thrombocytopenia according to the common terminology criteria for adverse events
(CTCAE4.0) occurred after the administration of Lenvatinib and the liver function was Child-Pugh class C 10 (Table 1). To reduce the adverse effect, Lenvatinib was reduced to $4 \mathrm{mg}$ per day and following this reduction no other treatment-related grade 3 or 4 adverse events were seen. Repeat imaging assessment after 4, 8, 12 cycles of combination treatment showed significant decrease in

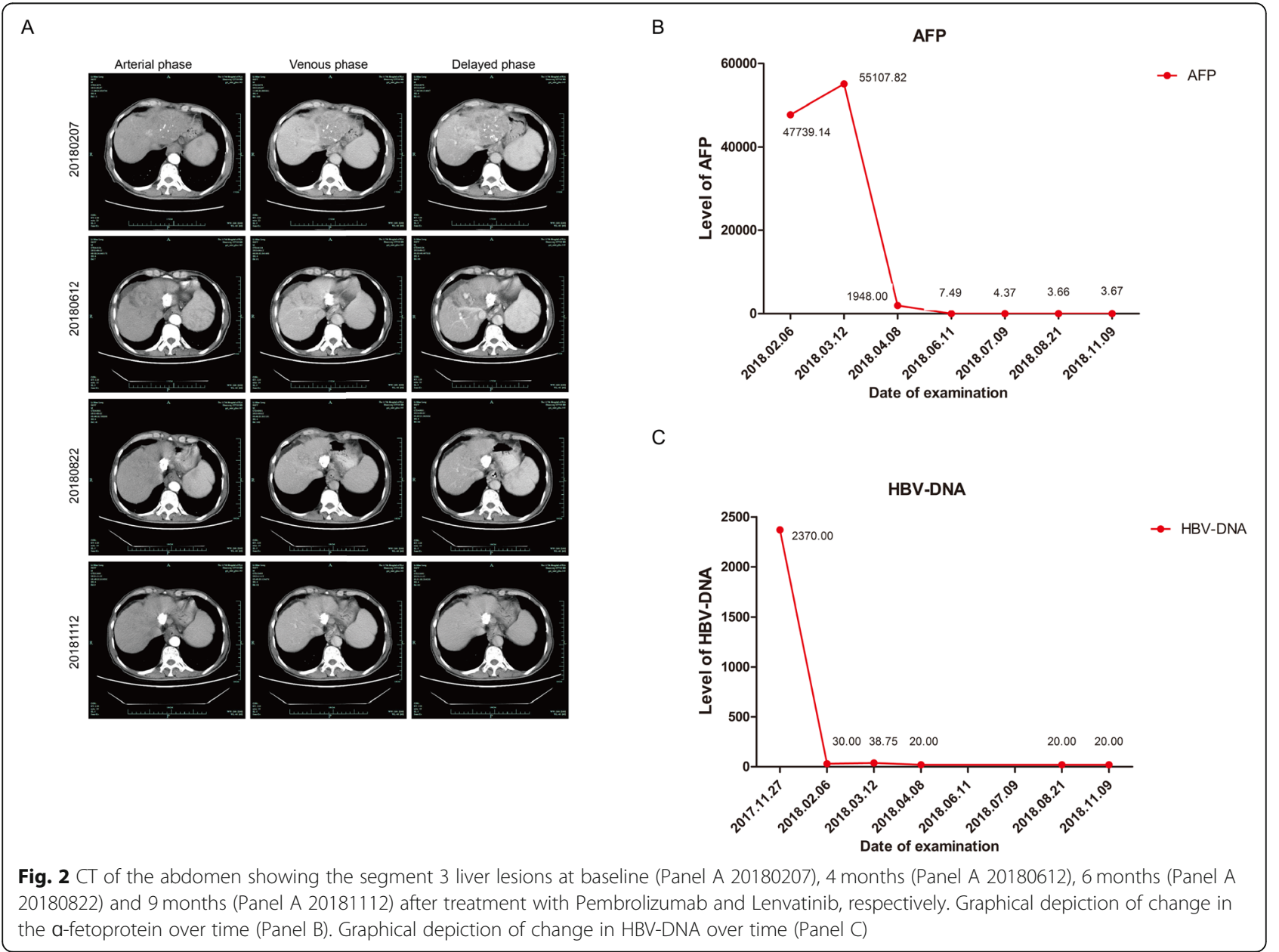


the size of the liver lesions (2018.06.12), and the subsequent CT scan (2018.08.22) also showed further shrinkage of the tumor and finally a complete response on 12th November 2018, with tumor assessment criteria as mRECIST (Fig. 2 a). AFP was also reduced to a normal range (Fig. 2 b). He remained on treatments with restaging scans every two months which has not shown evidence of recurrence to date. The Progression Free Survival is now 19 months and 22 months have elapsed since the diagnosis of HCC.

$A L B$ albumin, $H E$ hepatic encephalopathy, $P T$ prothrombin time, INR international standard ratio, $T-B I L$ total bilirubin, $W B C$ white blood cell, GR granulocyte, PLT platelet

$O R R$ objective response rate, $A E$ adverse event, $D L T$ dose limited toxicity, LEN Lenvatinib, PEM Pembrolizumab, MTD maximum tolerance dose, DOR duration of response, $d M M R$ mismatch repair deficient, $P F S$ progression-free survival, $O S$ overall survival, $C R$ complete response, $P D-L 1$ programmed cell death ligand 1, TMB tumor mutation burden

\section{Discussion and conclusion}

HCC is often diagnosed at advanced stages with limited curative therapy options, leading to a 5-year survival rate of $2 \%$ [1]. Conventional systemic therapy with cytotoxic drugs such as doxorubicin and cisplatin achieve low objective response rates (typically $<10 \%$ ), failing to improve the overall survival (OS) of these patients [3]. FOLFOX4 was compared to doxorubicin in a phase III trial and the PFS was greater for FOLFOX4, but the primary OS endpoint was not met [4].

The launch of sorafenib, a molecular kinase inhibitor, was thought to be a breakthrough in treating uHCC given the results in two randomized-controlled trials (SHARP trial [5] and Asia-Pacific trial [6]) although only 3 months longer OS was found in sorafenib group. Remaining the only FDA-approved therapy for a decade, the benefits of Sorafenib was limited for lack of either therapeutic alternative or second-line treatment for those who are intolerant to Sorafenib [7]. However, during the two-year period from 2017 through 2018, treatment for patients with advanced HCC is dramatically changed by novel multi-target inhibitors approved, Regorafenib, Lenvatinib, Cabozantinib, and single target Ramucirumab or immune checkpoint inhibitorsNivolumab and Pembrolizumab.

The efficacy of lenvatinib, a multitarget inhibitor, was proved in a phase 3 open-label, multicenter noninferiority trial, REFLECT study, and the results were published in the Lancet [8]. Median overall survival for lenvatinib was 13.6 months, compared to Sorafenib at 12.3 months (hazard ratio $0.92,95 \%$ CI $0.79-1.06$ ), meeting the study primary criteria for non-inferiority. As a result, the FDA approved Lenvatinib in a first-line setting for patients with unresectable advanced HCC in August 2018 [9].

In recent years, immune checkpoint blockade has brought a paradigm shift in the treatment of a number of malignancies. Various immune checkpoint blocking agents are being tested for their efficacy in HCC. Furthermore, the immune checkpoint blockade of programmed death receptor-1 (PD-1) pathway offers a potential treatment strategy based on the encouraging results of the phase I/II trial of Pembrolizumab (KEYNOTE-224) and Nivolumab (Checkmate 040 trial). KEYNOTE-224 is a non-randomized, multicenter, openlabel, phase 2 trial [10], 104 patients with advanced HCC who had progression on or intolerance to Sorafenib received Pembrolizumab $200 \mathrm{mg}$ every 3 weeks. Objective Response rate in 18 patients (17, 95\% CI 11-26\%) and severe adverse events in 16 of the 104 patients indicate its tolerability and efficacy. Nivolumab, another anti-PD1 antibody, was assessed in the Checkmate 040 trial for patients with advanced HCC. The objective response rate was about $20 \%$, the disease control rate was $64 \%$ and the median duration of response is 17 months for Sorafenib-naïve patients and 19 months for patients who had been previously treated with Sorafenib [11]. The FDA approved the use of Nivolumab in 2017 for patients with HCC who progressed on or after Sorafenib and the liver function is Child-Pugh A or $\mathrm{B}^{9}$. A phase III RCT, Checkmate 459, in which nivolumab is being compared to Sorafenib as first-line treatment in patients with advanced HCC is currently in progress (NCT02576509).

Currently, the first line options for uHCC include sorafenib and lenvatinib, and second line options are formed by Regorafenib, Nivolumab, Pembrolizumab, and Cabozantinib [9]. The combination of Lenvatinib and Pembrolizumab is a novel but potent competitor for the future gold standard in the systemic treatment of uHCC. Lenvatinib was proved to be an immunomodulator in tumor microenvironment [12] while PD-1 antibody blocks the co-inhibitory signals and unlocks the negative regulation of the immune response [13]. In the hepa1-6 hepatocellular carcinoma model, treatment with lenvatinib decreased the proportion of monocytes and macrophages population and increased that of CD8 $+\mathrm{T}$ cell populations, indicating the immunomodulatory activity of Lenvatinib [14]. This combination inhibited cancer immunosuppressive environments induced by tumorassociated macrophages and Tregs, reducing the levels of TGF- $\beta$ and IL-10, the expression of PD- 1 , and the inhibition of Tim-3, and thereby triggering anticancer immunity mediated by immunostimulatory cytokines such as IL-12 [15]. Therefore, further investigations for the combination treatment of Lenvatinib and Pembrolizumab are warranted to provide its efficacy data in 
clinical trials. We conducted a thorough English literature search on PubMed using the search terms 'anti-PD1,' 'pembrolizumab' or 'nivolumab,' 'lenvatinib' and 'hepatocellular cancer', 'HCC,' or 'hepatoma'. There are no published data from randomized controlled trials in HCC; however, an ongoing open-label phase $1 \mathrm{~b}$ trial (KEYNOTE 524, NCT03006926) (Table 2), is the only study on the combination treatment of Lenvatinib plus Pembrolizumab registered on clinicaltrial.gov currently. Preliminary results were presented in the form of a poster at the American Society of Clinical Oncology Annual Meeting in 2018. The study was designed into 2 parts, including dose limiting toxicity (DLT) evaluation and expansion parts to demonstrate its safety and efficacy, respectively. Patients of
uHCC with BCLC stage B or C, Child-Pugh Class A and no other systemic treatment (including Sorafenib) were enrolled for tolerability and efficacy (through CR or PR) assessments. They received Lenvatinib $12 \mathrm{mg}$ (body weight over $60 \mathrm{~kg}$ ) or Lenvatinib $8 \mathrm{mg}$ (body weight less than 60 $\mathrm{kg}$ ) orally once-daily and Pembrolizumab $200 \mathrm{mg}$ IV once 3 weeks as the standard regimen. No dose limited toxicities were reported in Part 1 of the study and 3 of the 24 deaths were considered treatment-related in Part 2. The most common treatment-emergent adverse events for any grades were decreased appetite (53.3\%), hypertension (53.3\%), diarrhea $(43.3 \%)$ and fatigue (40.0\%). Objective response rate, assessed by mRECIST is 11 out of 26 (42.3, 95\%CI 23.4-63.1), including 4 cases with unconfirmed

Table 2 Ongoing clinical trials with immune checkpoint blockade pembrolizumab and lenvatinib in solid tumors

\begin{tabular}{|c|c|c|c|c|c|c|c|}
\hline NCT number & $\begin{array}{l}\text { Number } \\
\text { of } \\
\text { patients }\end{array}$ & Cancer type & $\begin{array}{l}\text { Trial } \\
\text { phase }\end{array}$ & $\begin{array}{l}\text { Line of } \\
\text { therapy }\end{array}$ & $\begin{array}{l}\text { Gene or } \\
\text { protein } \\
\text { detection }\end{array}$ & Primary endpoints & $\begin{array}{l}\text { Current } \\
\text { status }\end{array}$ \\
\hline NCT03609359 & 29 & Advanced Gastric Cancer & 2 & & / & ORR & recruiting \\
\hline NCT03006887 & 6 & $\begin{array}{l}\text { Transitional Cell Carcinoma } \\
\text { Renal Cell Carcinoma } \\
\text { Clear Cell Renal Cell Carcinoma }\end{array}$ & $1 b$ & & / & 1.AE 2.DLT & $\begin{array}{l}\text { active, } \\
\text { not } \\
\text { recruiting }\end{array}$ \\
\hline NCT02501096 & 329 & $\begin{array}{l}\text { Tumors involving non-small cell lung cancer, renal } \\
\text { cell carcinoma, endometrial cancer, urothelial cancer, } \\
\text { squamous cell carcinoma of the head and neck, or } \\
\text { melanoma }\end{array}$ & $\begin{array}{l}1 \mathrm{~b}(\mathrm{LEN}) / \\
2(\mathrm{PEM})\end{array}$ & $\begin{array}{l}\text { Salvage } \\
\text { therapy }\end{array}$ & / & $\begin{array}{l}\text { 1.MTD (phase 1b) } \\
\text { 2.ORR 3.DLT }\end{array}$ & recruiting \\
\hline NCT03006926 & 104 & Hepatocellular Carcinoma & $1 b$ & & / & $\begin{array}{l}\text { 1.AE 2.DLT 3.ORR } \\
\text { 4.DOR by Mrecist } \\
\text { and RECIST } 1.1 \\
\text { based on IIR analysis }\end{array}$ & recruiting \\
\hline NCT03797326 & 180 & $\begin{array}{l}\text { Advanced Solid Tumors } \\
\text { Triple Negative Breast Cancer } \\
\text { Ovarian Cancer } \\
\text { Gastric Cancer } \\
\text { Colorectal Cancer } \\
\text { Glioblastoma } \\
\text { Biliary Tract Cancers }\end{array}$ & 2 & $\begin{array}{l}\text { Salvage } \\
\text { therapy }\end{array}$ & $\begin{array}{l}\text { dMMR for } \\
\text { Colorectal } \\
\text { Cancer }\end{array}$ & $\begin{array}{l}\text { 1.ORR 2.Percentage } \\
\text { of AE 3.Percentage } \\
\text { of Discontinue } \\
\text { Study Treatment }\end{array}$ & $\begin{array}{l}\text { not yet } \\
\text { recruiting }\end{array}$ \\
\hline NCT03776136 & 100 & Advanced Melanoma & 2 & & / & ORR & recruiting \\
\hline NCT03820986 & 660 & Malignant Melanoma & $\begin{array}{l}\text { 2(PEM)/ } \\
3(\mathrm{LEN})\end{array}$ & first-line & / & 1.PFS 2.OS & $\begin{array}{l}\text { not yet } \\
\text { recruiting }\end{array}$ \\
\hline NCT02973997 & 60 & Thyroid Gland Carcinoma & 2 & metastasis & / & $\begin{array}{l}\text { 1.CR rate } \\
\text { 2.Confirmed } \\
\text { response rate }\end{array}$ & recruiting \\
\hline NCT03829332 & 620 & Non-small Cell Lung Cancer & 3 & first-line & PD-L1 $\geq 1 \%$ & 1.PFS 2.05 & $\begin{array}{l}\text { not yet } \\
\text { recruiting }\end{array}$ \\
\hline NCT03713593 & 750 & Hepatocellular Carcinoma & 3 & first-line & / & 1.PFS 2.OS & recruiting \\
\hline NCT03517449 & 780 & Endometrial Neoplasms & 3 & & MMR & 1.PFS 2.OS & recruiting \\
\hline NCT03321630 & 24 & GastroEsophageal Cancer & 2 & $\begin{array}{l}\text { salvage } \\
\text { therapy }\end{array}$ & $\begin{array}{l}\text { correlative } \\
\text { biomarker } \\
\text { studies. }\end{array}$ & 1.ORR 2.OS & recruiting \\
\hline NCT03829319 & 726 & Nonsquamous Non-small Cell Lung Cancer & 3 & first-line & PD-L1 & $\begin{array}{l}\text { Part 1: DLT AE Part } \\
\text { 2: PFS OS }\end{array}$ & $\begin{array}{l}\text { not yet } \\
\text { recruiting }\end{array}$ \\
\hline NCT02811861 & 1050 & Renal Cell Carcinoma & 3 & first-line & / & PFS & recruiting \\
\hline NCT03516981 & 192 & Advanced Non-Small Cell Lung Cancer & 2 & & $\begin{array}{l}\text { Gene } \\
\text { expression } \\
\text { profile and } \\
\text { TMB }\end{array}$ & ORR & recruiting \\
\hline
\end{tabular}


responses. The estimated median duration of progressionfree survival was 9.69 months. Data above demonstrate the tolerability and encourage the antitumor activity of the combination therapy. Combination therapy of Lenvatinib and Pembrolizumab is a novel and potent therapeutic regimen for the uHCC. Although the clinical trial of this combination is still in phase $1 \mathrm{~b}$ and ongoing, preliminary results are encouraging for its safety and efficacy. The eligibility criteria for this trial includes BCLC stage B (not applicable for transcatheter arterial chemoembolization (TACE)) or C, Child-Pugh class A, ECOG performance status $0-1$, which means the preserved liver function is good among the patients enrolled. There is no report on the efficacy of this combination for patients whose ChildPugh at class B with cirrhosis at the decompensation stage. Our case was diagnosed of HCC with ascites, cirrhosis, splenomegaly, and portal vein hypertension at his first visit at the emergency department, indicating the deterioration of the liver function. Irregular Lenvatinib 8 mg-4 mg (lower dose because of intolerance of the adverse effect) usage and 7 cycles of Pembrolizumab $100 \mathrm{mg}$ $(2 \mathrm{mg} / \mathrm{kg}$ ) injection with an interval of 3 to 4 weeks dramatically decreased the AFP from $47,739.14 \mathrm{ng} / \mathrm{ml}$ to the normal range and reached CR according to mRECIST. The PFS is 19 months and 22 months had elapsed since the diagnosis of HCC. So, the responses appear to be durable. Further follow-up for this patient is ongoing. The complete response of Lenvatinib in REFLECT trial or Pembrolizumab in KEYNOTE-224 trial is both $1 \%$, so even for patients with good ECOG status and enough liver function, $\mathrm{CR}$ is not very common. The great success in this case demonstrates the possible feasibility of the combination treatment in $\mathrm{uHCC}$ at decompensate stage ((BCLC C and Child-Pugh class B Score 8) for patients who are not suitable for sorafenib due to poor liver function. Standard combination and sequencing of the therapy need to be established with deeper insight into the rationale of combined action and further RCTs. What's more, the patients enrolled in, for most of the cases, present with preserved liver function, while the advanced HCC patients in real clinical phase may have a much worse performance. Whether they can tolerate the combination treatment is still unknown and the clinical trials won't take the risk to enroll these patients. No life-threatening adverse events were found in our patient according to treatment due to a decrease in the dosage of both PEM and LEN. Notably, there are many ongoing trials to evaluate the safety and efficacy of checkpoint inhibitors and Lenvatinib in solid tumors (Table 2), and a subgroup of NCT02501096 (Table 2) showed anti-tumor activity in patients with advanced recurrent endometrial cancer with a safety profile that was similar to those previously reported for Lenvatinib and Pembrolizumab monotherapies, apart from an increased frequency of hypothyroidism [16].
Serum level of HBV DNA should be considered for surveillance of $\mathrm{HBV}$-infected patient who receive immunotherapy. The patient had a high HBV DNA level of $2.37^{*} 10^{\wedge} 3 \mathrm{IU} / \mathrm{ml}$ at first diagnosis followed by HBV DNA level below $30 \mathrm{IU} / \mathrm{ml}$ after antiviral treatment with entecavir and below $20 \mathrm{IU} / \mathrm{ml}$ during follow up.

There are a few potential factors discussed to estimate prognosis, including emergent adverse AFP, PD-L1, requiring further evidence to verify their potency in this novel combination treatment. AFP (over $400 \mathrm{ng} / \mathrm{mg}$ ) and PD-L1 (over 1\%) are reviewed as potential biomarkers to estimate the prognosis in certain treatment regimen of HCC patients whereas neoantigen, tumor mutational burden, and interferon gamma need further investigation [17]. Notably, our patient lacked diagnosis that was confirmed by pathology and without data of PD-L1 expression, we recommended the gene examination of peripheral blood ctDNA, but the patient refused to pay for this additional testing. Even without the benefit of PD-L1 expression data he still got a good response for this combination treatment, which raises questions about the value of PD-L1, dMMR, or TMB testing as a biomarker in HCC when immunotherapy is combined with other therapies. Whether this great success could be duplicated is still unknown. Exploration of the possible indicators for the combination and prognosis estimating factors are the foundation for a wider application.

Other anti-angiogenic/immunotherapy combinations are also currently popular subjects for research. An Atezolizumab (atezo) and Bevacizumab (bev) regimen was welltolerated and had a manageable safety profile in patients with microsatellite-high (MSI-high) metastatic colorectal cancer (mCRC), according to results of a preliminary clinical evaluation presented at the 2017 Gastrointestinal Cancers Symposium. The overall response rate was $40 \%$ using the RECIST criteria and 30\% via immune-related response criteria (irRC) [18]. Another study of Regorafenib plus nivolumab in patients with advanced gastric or colorectal cancer (REGONIVO, EPOC1603) was published at ASCO 2019, the ORR and DCR was 40 and $88 \%$ respectively [19]. Studies of Bevacizumab in combination with Atezolizumab in patients with untreated melanoma brain metastases (NCT03175432), NSCLC (NCT03836066), recurrent or metastatic squamous-cell carcinoma of the head and neck (NCT03818061) are ongoing.

In summary, what we could learn from this case is that the combination treatment of LEN and PEM with decreased dose and prolonged interval may be tolerable and effective among unresectable HCC patients with cirrhosis (those with hepatitis B infection) at a decompensated stage. While our case highlights some important aspects of the use of combination therapy, especially in $\mathrm{HCC}$ cases that lacked definitive expression of PD-L1 or 
dMMR, the potential side effects of the combination treatment should be highly concerned, and fully discussed with the patients in clinical practice. Lenvatinib plus Pembrolizumab may present a new potential treatment option for the sub-population. However, its efficacy and safety need further investigation in a randomized phase 3 study.

\begin{abstract}
Abbreviations
AE: adverse event; AFP: a-fetoprotein; ALB: Albumin; BCLC: Barcelona Clinic Liver Cancer; CR: Complete response; CT: Computerized tomography; ctDNA: circulating tumor DNA; DLT: Dose limited toxicity; dMMR: mismatch repair deficient; DOR: Duration of response; ECOG: Eastern Cooperative Oncology Group; GR: Granulocyte; HAE: Hepatic arterial embolization; HBV: Hepatitis B virus; HCC: Hepatocellular carcinoma; HE: Hepatic encephalopathy; IL-10: interleukin-10; INR: international standard ratio; IV: intravenous; LEN: Lenvatinib; mRECIST: modified response evaluation criteria in solid tumors; MTD: Maximum tolerance dose; ORR: Objective response rate; OS: Overall survival; PD-1: Programmed death receptor-1; PDL1: Programmed cell death ligand 1; PEM: Pembrolizumab; PFS: progressionfree survival; PLT: Platelet; PT: Prothrombin time; TACE: Transcatheter arterial chemoembolization; T-BIL: Total bilirubin; TGF- $\beta$ : Transforming growth factor$\beta ;$ TIM-3: T cell immunoglobulin domain and mucin domain-3; TMB: Tumor mutation burden; uHCC: unresectable hepatocellular carcinoma; WBC: White blood cell
\end{abstract}

\section{Acknowledgements}

The authors would like to thank the patient's family for giving consent and for providing the detail information of this case.

\section{Author's contributions}

LZN and LXJ wrote the manuscript. XYC analyzed the data and provide guidance. HXQ took care of the patient. WX provided the data of this case. All authors have read and approved the manuscript.

\section{Funding}

This study was supported by the Zhejiang Provincial Natural Science Foundation of China (Grant No. LY14H160045) and the Hangzhou Science and Technology Commission (Grant No. 20140633B41).

\section{Availability of data and materials}

All relevant data and diagnostic results are contained. The raw data is not made available in consideration of confidentiality.

\section{Ethics approval and consent to participate}

This study has been approved by Ethic Committee of the 903rd Hospital of PLA. The patient and his relations have signed an informed consent.

\section{Consent for publication}

The patient and his family were informed that the information published may potentially compromise anonymity. Publication was consented by the patient. Written informed consent was obtained from the case patient for publication of this report and any accompany images. A copy of the written consent is available for review by the Editor of this journal.

\section{Competing interests}

The authors declare that they have no competing interests.

Received: 12 June 2019 Accepted: 24 October 2019

Published online: 08 November 2019

\section{References}

1. Siegel RL, Miller KD, Jemal A. Cancer statistics, 2019. CA Cancer J Clin. 2019; 69(1):7-34.

2. Cronin KA, Lake AJ, Scott $S$, et al. Annual report to the nation on the status of Cancer, part l: national cancer statistics. Cancer. 2018;124(13):2785-800.

3. Stotz M, Gerger A, Haybaeck J, Kiesslich T, Bullock MD, Pichler M. Molecular targeted therapies in hepatocellular carcinoma: Past, Present and Future. Anticancer Res. 2015;35(11):5737-44.
4. Qin S, Cheng Y, Liang J, Shen L, Bai Y, Li J, Fan J, Liang L, Zhang Y, Wu G, Rau KM, Yang TS, Jian Z, Liang H, Sun Y. Efficacy and safety of the FOLFOX4 regimen versus doxorubicin in Chinese patients with advanced hepatocellular carcinoma: a subgroup analysis of the EACH study. Oncologist. 2014;19(11):1169-78.

5. Palmer DH. Sorafenib in advanced hepatocellular carcinoma. N Engl J Med. 2008;359(23):2498 author reply 2498-2499.

6. Cheng AL, Kang YK, Chen Z, et al. Efficacy and safety of sorafenib in patients in the Asia-Pacific region with advanced hepatocellular carcinoma: a phase III randomised, double-blind, placebo-controlled trial. Lancet Oncol. 2009;10(1):25-34

7. Tovoli F, Negrini G, Benevento F, Faggiano C, Goio E, Granito A. Systemic treatments for hepatocellular carcinoma: challenges and future perspectives. Hepat Oncol. 2018;5(1):HEP01.

8. Kudo M, Finn RS, Qin S, et al. Lenvatinib versus sorafenib in first-line treatment of patients with unresectable hepatocellular carcinoma: a randomised phase 3 non-inferiority trial. Lancet (London, England). 2018; 391(10126):1163-73.

9. Mody K, Abou-Alfa GK. Systemic therapy for advanced hepatocellular carcinoma in an evolving landscape. Curr Treat Options in Oncol. 2019;20(2):3.

10. Zhu AX, Finn RS, Edeline J, et al. Pembrolizumab in patients with advanced hepatocellular carcinoma previously treated with sorafenib (KEYNOTE-224): a non-randomised, open-label phase 2 trial. Lancet Oncol. 2018;19(7):940-52.

11. El-Khoueiry AB, Sangro B, Yau T, Crocenzi TS, Kudo M, Hsu C, Kim TY, Choo SP, Trojan J, Welling THR, Meyer T, Kang YK, Yeo W, Chopra A, Anderson J, Dela Cruz C, Lang L, Neely J, Tang H, Dastani HB, Melero I. Nivolumab in patients with advanced hepatocellular carcinoma (CheckMate 040): an open-label, non-comparative, phase 1/2 dose escalation and expansion trial. Lancet. 2017;389(10088):2492-502.

12. Lin YY, Tan CT, Chen CW, Ou DL, Cheng AL, Hsu C. Immunomodulatory effects of current targeted therapies on hepatocellular carcinoma: implication for the future of immunotherapy. Semin Liver Dis. 2018;38(4): 379-88.

13. Kudo M. Immuno-Oncology in Hepatocellular Carcinoma: 2017 Update. Oncology. 2017;93(Suppl 1):147-59.

14. Kimura T, Kato Y, Ozawa Y, et al. Immunomodulatory activity of lenvatinib contributes to antitumor activity in the Hepa1-6 hepatocellular carcinoma model. Cancer Sci. 2018;109(12):3993-4002.

15. Kato $Y$, Bao X, Macgrath $S$, et al. Lenvatinib mesilate (LEN) enhanced antitumor activity of a PD-1 blockade agent by potentiating Th1 immune response. Annals of Oncology. 2016, 27(suppl_6).

16. Makker V, Rasco D, Vogelzang NJ, Brose MS, Cohn AL, Mier J, Di Simone C, Hyman DM, Stepan DE, Dutcus CE, Schmidt EV, Guo M, Sachdev P, Shumaker R, Aghajanian C, Taylor M. Lenvatinib plus pembrolizumab in patients with advanced endometrial cancer: an interim analysis of a multicentre, open-label, single-arm, phase 2 trial. Lancet Oncol 2019: S14702045(19)30020-8.

17. Contratto M, Wu J. Targeted therapy or immunotherapy? Optimal treatment in hepatocellular carcinoma. World J Gastrointest Oncol. 2018;10(5):108-14.

18. Hochster HS, Bendell JC, Cleary JM, et al. Efficacy and safety of atezolizumab (atezo) and bevacizumab (bev) in a phase lb study of microsatellite instability (MSI)-high metastatic colorectal cancer (mCRC). J Clin Oncol. 2017;35 (suppl 4S; abstract 673).

19. Fukuoka S, Hara H, Takahashi N, et al. Regorafenib plus nivolumab in patients with advanced gastric (GC) or colorectal cancer (CRC): An openlabel, dose-finding, and dose-expansion phase $1 \mathrm{~b}$ trial (REGONIVO, EPOC1603). ASCO, 2019, ABSTRACT 2522.

\section{Publisher's Note}

Springer Nature remains neutral with regard to jurisdictional claims in published maps and institutional affiliations. 